Latino Studies Volume 16 Number 1

ORIGINAL PAPER

\title{
Investigating intra-ethnic divisions among Latino immigrants in Miami, Florida
}

\section{Marie L. Mallet}

Sorbonne Law School

Marie-laure.mallet@univ-paris1.fr

\section{Joanna M. Pinto-Coelho}

Bryn Mawr College

ipintocoel@brynmawr.edu

\section{Abstract}

The demographic diversification of the Latino population, in terms of both generational change and national origin, calls for the exploration of intra-group dynamics within the oftenasserted but rarely investigated Latino communities. These demographic shifts are particularly salient in the Miami-Dade County, Florida, metropolitan area, making it an ideal case study for investigating pan-ethnic social cohesion and divisions. This article analyzes forty-five semi-structured qualitative interviews with Latino immigrants in Miami from ten nationalities to understand how immigrants from various countries perceive divisions among each other and how these perceptions affect their interactions. We find the most significant divisions to exist between Caribbean Latinos and Continental Latin American Latinos.

\section{Keywords}

Latino, Immigrants, Pan-ethnicity, Miami, Intra-ethnic division, Secondary marginalization

\section{About the Authors}

Marie L. Mallet is Assistant Professor at the Sorbonne Law School. She received her PhD in 2013 from the Sorbonne University. She is a Fulbright alumna and a Marie Curie fellow. Her research interests include immigration and race relations in the United States and in Europe, and focus more specifically on Latino immigrants and their integration into a host society.

Joanna M. Pinto-Coelho earned an MS in social policy and a PhD in sociology from the University of Pennsylvania and is currently a visiting assistant professor at Bryn Mawr 
Latino Studies Volume 16 Number 1

ORIGINAL PAPER

College. Her research interests include racial residential segregation, racial and ethnic

inequality in the American higher education system, and the integration of Latin American immigrants into global gateway cities. 
Latino Studies Volume 16 Number 1

ORIGINAL PAPER

\section{Latino pan-ethnicity}

As the number of Latinos in the United States has grown rapidly over the last five decades, interest in the population as a whole has overshadowed inquiry across lines of difference, including those defined by race, class, and national origin. The purposive social construction of the "Hispanic” and "Latino” pan-ethnic labels and a singular political, economic, racial, and sociocultural conception of American latinidad has occluded, often by design, the differences that exist within this diasporic constellation of communities (Mora 2014).

A growing body of research critiques Latino pan-ethnicity as a social and political construct (e.g., Garcia Bedolla 2014; Fernández 2012; Beltrán 2010). But most empirical studies that include or focus on Latinos do not disaggregate them across lines of difference. Even fewer studies explore the relations between and among Latino national origin groups and how the nature of these interactions impacts the populations in question, with notable exceptions such as the works of Garcia Bedolla (2005, 2014); Aranda et al. (2014); Fernández (2012); Marrow (2011); and De Genova and Ramos-Zayas (2003).

Some argue that pan-ethnic cohesion leads to politically and socially desirable outcomes, which was the primary driving force behind the intentional rhetorical construction of Latinos as a pan-ethnic group (Mora 2014). Whether it is desirable or not remains debatable, but the fact remains that both social cohesion and social division exist within the larger Latino community, and it is critical to address how intra-ethnic differences affect intraethnic dynamics and interactions when seeking to understand these phenomena.

In this article, we analyze the results of forty-five in-person interviews with Latino immigrants from ten different national origin groups in Miami-Dade County. The interviews were conducted as part of a larger study that did not itself focus on the topic of Latino cohesion and/or divisions, but these topics arose nonetheless. The original survey data 
Latino Studies Volume 16 Number 1

ORIGINAL PAPER

questioned the existence of a single latinidad. Though we do not deny the existence of Latino pan-ethnic cohesion, our results in this particular study highlight divisions among Latino groups, particularly between Latinos from the Caribbean and those from continental Latin America. We aim to fill a gap in the existing literature on intra-group dynamics by analyzing these intra-Latino divisions in order to improve our understanding of both division and cohesion among minority co-ethnics.

\section{Cultural cohesion and identity formation among Latinos}

\section{Immigrants, identity, and social cohesion}

In this context, we define social cohesion as an acknowledgement and celebration of fundamental similarities, including a shared set of cultural or social characteristics, among subgroups within a larger pan-ethnic community —in this case, national origin groups under the umbrella of the larger "Latino" label. Intra-ethnic cooperation can serve desirable outcomes such as collective action. For instance, ethnic solidarity among immigrants from different nations has led to the organization of labor unions (Milkman 2007) and is correlated with greater pan-ethnic social mobility and increased pan-ethnic socioeconomic status (Brown and Brooks 2006). On the other hand, intra-ethnic competition can lead to negative attitudes toward immigrants (Carey et al. 2013), and can therefore heighten tension and conflict among Latinos (Bohon 2013). Researchers, not to mention the media and the more general public, essentialize Latinos as a monolithic group, and often racialize them, as a racial group alongside whites, blacks, and Asians (Telles and Ortiz 2009). To wit, this racialization—defining Latinos as a racial group and subsequently devaluing them, their phenotypic characteristics, language, and culture within the framework of the existing racial hierarchy (Cobas et al. 2009)—occurred alongside the very purposeful advancement of panethnic terms like "Hispanic” and "Latino" and the social, political, and economic agendas with which those pan-ethnic terms were inextricably entwined (Mora 2014). By failing to 
Latino Studies Volume 16 Number 1

ORIGINAL PAPER

analyze intra-ethnic difference and division, most research that racializes Latinos also assumes an unproblematic pan-ethnic social cohesion (Beltrán 2010; Cobas et al. 2009). This is why it is essential to understand the factors both uniting and dividing Latinos, as these factors are significant throughout society.

One way social cohesion can be assessed is by analyzing ethnic identity, which can measure the integration of immigrants by determining their level of adoption of the host society's culture and their degree of retention of their own (Phinney et al. 2001). Studies have shown that immigrants' ethnic identity evolves over time (Tovar and Feliciano 2009; Phinney and Ong 2007) and in response to political, economic, and social contexts (Sabatier 2008; Tovar and Feliciano 2009). For instance, ethnic identity becomes more salient when immigrants experience discrimination (Sanchez 2006), particularly in their interactions with non-Hispanic whites (Weaver 2007), blacks (McClain et al. 2006), and Asians (Johnson 2004). When minorities perceive that they are the targets of prejudice and unfair treatment, they tend to close ranks with their co-ethnics (Stepick and Stepick 2002) and reactivate ethnic ties (Portes and Rumbaut 2001) as coping mechanisms.

However, these studies rarely investigate how intra-ethnic subgroup interactions may affect identity formation or how identity formation phenomena may, in turn, affect the dynamics of societal integration. That is, studies tend to examine dynamics between socially constructed groups by race and/or ethnicity but not within any given race and/or ethnicity. This article addresses this critical yet understudied phenomenon.

\section{Intra-Latino relations}

The body of literature that analyzes within-group interactions among Latinos is limited, and this research often focuses on attitudes and behaviors within the bounds of one specific national origin group at a time. If the literature disaggregates the Latino pan-ethnic group, it often focuses on descriptive socioeconomic differences (Guarnaccia et al. 2007). 
Latino Studies Volume 16 Number 1

ORIGINAL PAPER

Studies have highlighted the lower socioeconomic status and overall achievement of

Mexicans and Puerto Ricans in comparison with other Latino groups (Telles and Ortiz 2009;

Portes and Rumbaut 2001; Aranda 2007; Grosfoguel 1999), contrasting them with the rapid upward economic integration of Colombians and Cubans (Aguilar 2009; Perez 1986; Grenier et al. 2002). Existing research has also demonstrated that specific national groups, such as Mexicans and Puerto Ricans, are racialized more often than other Latino national groups (Alba et al. 2014), which affects their identity formation and integration. Indeed, race and skin color are important factors in the integration process of Latino immigrants, and immigrants with lighter skin color tend to experience a higher degree of socioeconomic incorporation than their darker-skinned counterparts (Woltman and Newbold 2009). Horton (2004) showed that Mexican and Cuban immigrants experienced distinctly different responses when accessing care in one public health care institution: the former, categorized as “undeserving," were discouraged by service providers from seeking health care, while the latter, perceived as more “deserving citizens,” were not.

Some studies, however, have analyzed the interactions among the different national origin Latino groups. The first and most foundational is Felix Padilla's (1985) work on ethnic consciousness among Latinos in Chicago in the mid-twentieth century. He contends that Chicano and Puerto Rican shared experiences of economic and racial marginalization led to the emergence of a pan-ethnic consciousness. Helen Marrow’s work (2011) on immigrants in North Carolina, a “new” immigrant destination, addresses how Latinos relate to each other in the context of the industries in which they work. She finds that South Americans and Puerto Ricans are more likely to be in managerial positions, whereas Mexican immigrants are more likely to occupy lower-level positions. Marrow investigates the dialectic between these structural inequalities and the tense intergroup relationships they produce. In their 2003 book Latino Crossings, De Genova and Ramos-Zayas show that deep cultural divisions between 
Latino Studies Volume 16 Number 1

ORIGINAL PAPER

Mexicans and Puerto Ricans in Chicago are reinforced by the variations in the Spanish they speak, which in turn facilitate the racialization of class differences. To them, "the prospect of community formation among distinct national-origin groups on the basis of a shared sense of Latino identity . . . never ceases to be problematic” (2003, p. 20). Their study analyzes the influence of intra-ethnic subgroup interactions within the frame of the dominant black and white racial dichotomy. Jiménez (2010) further analyzed the boundaries that divide the Mexican communities along the lines of nativity, language ability and ethnic identity. The American racial stratification system is central to our analysis, but this paper also aims to bring more nuance to the discussion.

Finally, Aranda et al. (2014) discuss the nature of race and ethnic relations among Latinos in Miami, Florida. They find that Latinos who hail from South America and the Caribbean tend to look down on Central Americans and, to a lesser extent, Mexican Americans. They express this behavior using language that suggests cultural racist frameworks based on social class differences. Moreover, other Latinos hold antagonism toward Cubans because of their instant path to legal immigration status.

The purpose of this study is to investigate the prospect of whether any of these patterns of cohesion or division hold true in our data. As with Aranda et al. (2014), we also focus on Miami, but we find yet another level of division — that between Latinos from the Caribbean and from continental Latin America. We adapt the concept of secondary marginalization, as developed by Cohen (1999), to analyze our empirical evidence.

\section{Secondary marginalization}

Embedded in the implicit assumption of Latino cohesion are the reasons why panethnic unity could help Latinos. By virtue of being treated as a monolithic group, Latinos can use their numbers to their advantage. Indeed, Latinos in the United States, and in Miami, are considered in the political sphere as a special interest minority group. As is the case with any 
Latino Studies Volume 16 Number 1

ORIGINAL PAPER

minority group in the United States, this status can potentially confer special privileges under affirmative action. Furthermore, in places like Miami, where Spanish is the most common spoken language and where Latinos dominate not only numerically but in the political and economic spheres, there is another implicit assumption at work, tied to Latino group membership. Outsiders assume that Latinos are more welcome in Miami, where they no longer are a minority group, than elsewhere in the country, and should therefore take advantage of their pan-ethnic group membership in order to help each other against competitors of other races and ethnicities.

Setting these reasons for embracing pan-ethnic identity aside, there are instrumental reasons to drop the Latino label in favor of meso-level affinity monikers. First, when minority groups cease to experience primary marginalization from the majority group, as may be the case for Latinos in Miami, they may choose to reinforce differences among themselves, along lines of difference such as race, national origin, and class. These phenomena exist less often in places where Latinos are not a majority and where the dynamics are focused on Latinos versus whites or Latinos versus blacks. Second, previous work has shown that some members of a minority group turn against their co-ethnics, aiming to distance themselves from the larger group because they view group membership, or the perception thereof, as being detrimental to their personal social mobility (Ochoa 2000; Guarnizo et al. 1999; Lavariega Monforti and Sanchez 2010). Cathy Cohen’s development of the concept of “secondary marginalization” in The Boundaries of Blackness (1999) shows how marginalized identities relevant to class, gender, and sexuality challenge accepted ideas of who enjoys the privileges associated with community membership.

The literature on Latinos focuses primarily on (Padilla 1985; Calderón 1992; Sanchez 2006) or assumes (Frey and Farley 1996; Catanzarite and Aguilera 2002; Bohon 2013) group cohesion. By essentializing all Latinos as a monolithic group, without investigating or 
Latino Studies Volume 16 Number 1

ORIGINAL PAPER

acknowledging the heterogeneity of the group, and therefore assuming a pan-ethnic unity that is unproblematic, one undermines a more holistic, nuanced analysis that would include the possibility of another intra-Latino dynamic — division. If divisions exist, they could both reflect and play a significant role in (re)producing secondary marginalization. In this article, we therefore adapt the concept of secondary marginalization to investigate our research question: Do Latinos in Miami experience intra-group divisions and, if so, to what extent and around what bases?

In the case of Miami, we recognize that secondary marginalization likely applies differently. First, Latinos in Miami-Dade County may no longer experience the same levels of primary marginalization from non-Hispanic whites, due in part to their numerical dominance (see below). However, even if they are the majority at the local level in Miami and therefore do not experience primary marginalization in their daily lives, they are still, at both the state and national levels, an ethnic minority group. Some members of Latino communities in Miami, such as the Cubans, for instance, still strive to advance their own interests at the local, state, and national levels. Second, this concept did not initially take into account factors such as national origin and generational status-indeed, it analyzes intragroup relations among African Americans, a group that is not considered as immigrants. Therefore, such variables were not pertinent for the analysis developed by Cohen in 1999. Therefore, we adapted this concept to better represent the diversity of the Latino populations in the United States in general and in Miami in particular.

Analyzing our results through the lens of the secondary marginalization process is still relevant for several reasons. The Latino communities in Miami have adapted to and internalized the United States' racial stratification, in addition to the racialized hierarchies from their country of origin (see Maldonado 2009; Dzidzienyo and Oboler 2005). As a result, Latinos tend to replicate some of the behaviors of the dominant (Anglo/non-Hispanic whites) 
Latino Studies Volume 16 Number 1

ORIGINAL PAPER

group (Bonilla-Silva 2002), creating boundaries between those they perceive to be at the top and at the bottom of the hierarchy among Latino communities. However, very few studies show that specific Latino subgroups try to endear themselves to, or distance themselves from, other particular subgroups. The present article therefore builds on previous research on intragroup interactions, increased contact, and identity formation, yet also aims to begin filling this gap in the literature by focusing on the mechanisms of Latino intra-group dynamics, particularly that of division. We would like to repeat, however, that just because we focus on intra-ethnic division in this paper does not mean that intra-ethnic cohesion is not present within Latino communities in general, or within our sample more specifically.

\section{Interviewing Latino immigrants in Miami}

In this sociological study, the authors analyze forty-five semi-structured interviews with Latin American immigrants from ten countries in Mexico, Central America, South America, and the Caribbean. We employ the theoretical framework of secondary marginalization theory to understand how the Miami Latinos under study negotiated their ethnic identities.

\section{The choice of Miami}

This study is limited to Miami-Dade County, and focuses on several incorporated cities and neighborhoods within, where the interviews were conducted. Miami’s rich history and diverse present make it an excellent case study in which to examine the role of the interactions among Latino communities. It is an ideal site for the study of cohesion and division among Latino national origin groups for several reasons.

First, Miami is the only metropolitan area, aside from the San Antonio, Texas, area, with a majority Latino population (Portes and Stepick 1993). Two-thirds of Miami-Dade County’s population identifies as Latino (Miami-Dade County QuickFacts 2015). In this way, then, it is possible for us to study Latinos where they, not whites, are the referent group in the 
Latino Studies Volume 16 Number 1

ORIGINAL PAPER

geographical area (Aranda et al. 2014). Second, Miami has become more intra-ethnically diverse in recent years, such that the Cuban population is no longer such an overwhelming majority. While Miami can be characterized as an older immigrant gateway region, in some ways it could also be characterized as a newer immigrant destination because of the more recent waves of immigrants from Mexico, as well as other Caribbean, Central and South American countries. As of the 2010 census, Cubans made up 54\% of the Latino population (34\% of the overall population), compared with Mexicans at 3\%, Puerto Ricans at 6\%, and other Latinos at 38\% (Miami-Dade County, Department of Planning and Zoning 2011). In other words, the Cuban story is not the only Latino story in Miami, and it is more possible now than it was before to compare and contrast the experiences of multiple Latino ethnic groups with empirical validity. Third, and related to this second point, is Miami's particular history with immigration, class, and race. Miami’s historical ties with Cuba and its location as the southernmost publicly accessible major city in Florida — and the United States—made it the preferred gateway for many Cuban immigrants, who, until January 2017, benefited from the "wet foot/dry foot" policy, granting them a privileged status in the United States compared with immigrants from other countries.

\section{Interviews}

The data for this article derive from a collection of forty-five semi-structured qualitative interviews with a broad array of Latino immigrants in Miami collected in 2012 as part of a larger multi-area study examining dynamic relationships among Latino groups in the United States. The first language of all the respondents was Spanish, so 95\% of the interviews were conducted in that language. The exploratory interviews lasted between forty and ninety minutes, and averaged about fifty minutes each. Refer to the respondent profile in figure 1 for more details. 
[Figure 1 about here]

Respondents were selected through a purposive sampling process that was designed to enhance their diversity. Contact with respondents was established through participation in neighborhood meetings, political gatherings, religious ceremonies, and community celebrations and festivals. To achieve racial, socioeconomic, and national origin heterogeneity within the sample, the recruiting process was repeated in neighborhoods that varied by these characteristics, including but not limited to Hialeah, Kendall, Key Biscayne, and Little Havana. Once the first interviews were completed, the snowball method was used to diversify and increase the existing sample size. These two sampling techniquespurposeful and snowball—made it possible to obtain a sample stratified by legal status and country of origin. ${ }^{1}$ This paper includes respondents from ten Latino groups in particular: Argentines, Colombians, Cubans, Dominicans, Guatemalans, Hondurans, Mexicans, Puerto Ricans, ${ }^{2}$ Nicaraguans, and Salvadorans. These groups are a representative cross section of Latinos from North America, Central America, South America, and the Caribbean.

The first author conducted interviews using a semi-structured design that included five main sections. First, respondents were asked about their immigration story and the reasons they came to the United States and Miami in particular. Second, they were asked about their current life in the United States, including their living conditions and personal situation. Third, they were asked to describe a typical day. The fourth section explored how respondents perceived their life in Miami, whether they were involved in their community, and the scope and nature of their social networks. Finally, respondents were asked about their perceptions about race relations and discrimination in Miami and about their interactions with other Latinos from other national origins. Respondents were free to expound on topics as they liked. 
Latino Studies Volume 16 Number 1

ORIGINAL PAPER

The interviews were transcribed in their original language and those conducted in Spanish were translated into English by the first author, who is bilingual (English/Spanish). They were then coded by the first author using qualitative data analysis software (Atlas.ti) in two rounds: first, based on the interview guide, and second, to codify information that was not initially present in the initial codebook but emerged as relevant during the first round of coding. Their answers were coded qualitatively in Atlas.ti and quantitatively in Excel. The first author analyzed interviews and the coded results in the network view she built in Atlas.ti. The network view facilitates the presentation of complex information by mapping the connections between the various codes. It helps visualize and explore conceptual structures and links. The main arguments in this paper were drawn from the data as they emerged through the second round of coding. The first author then selected the empirical evidence to illustrate the main arguments of this article, choosing and translating quotes for their representativeness and clarity. All names used in the paper are pseudonyms.

\section{Limitations}

There were several limitations to our paper. First, we interviewed only immigrants, most of whom spoke better Spanish than English. The reason behind this choice lies in the fact that in the United States, almost half (48.7\%) of the adult Latino population is foreignborn (Pew Hispanic Center 2015). That figure is even higher in Miami (51.5\%). The fact that all respondents were first-generation immigrants means that this group is among the least likely of Latino subgroups to feel any sense of pan-ethnic unity or cohesion, and the most likely to feel divided according to national origin (Beltrán 2010). Second, our focus on Miami provided an excellent opportunity to focus on secondary marginalization within the context of a truly unique metropolitan area, but results from the area may not be generalizable to other metropolitan areas where Latinos are the numerical minority. Third, we reported on and analyzed only instances of divisions and competition among Latinos in order to illuminate a 
Latino Studies Volume 16 Number 1

ORIGINAL PAPER

counternarrative to that which is dominant in the literature and the media. Fourth, this paper investigates intra-Latino conflict using interviews — and thus analyzes attitudes. Attitudinal research risks capturing more sniping and stereotyping (e.g., De Genova and Ramos-Zayas 2003) than behaviors, which are equally if not more important in social science research. Our interviews did reveal that some Latinos do believe negative stereotypes about other Latino groups. The sharing of these negative and politically incorrect views may suggest, however, that individual interviews allowed respondents to share genuine beliefs that they may otherwise have kept to themselves in mixed company, including focus groups or even participant observation.

Future research could interview second-, third-, or even later-generation Latinos with different facilities with both Spanish and English; engage respondents in other regions of the country with different demography; and investigate the root causes of intra-ethnic social cohesion.

\section{Aspects of intra-Latino group division}

This article analyzes the dynamics of division in the intra-group interactions among the Latino communities in Miami. The theoretical significance of this paper is how it analyzes Latino intra-group dynamics in a new light: while the literature tends to over-report cohesion without investigating its corollary, this paper focuses on intra-ethnic divisions.

Contrary to common belief and what the literature tends to argue, our results suggest that intra-group interactions among the Latino communities are not only characterized by pan-ethnic cohesion, but are also marked by strife, as Latinos experience negative social and economic interactions with their co-ethnics. In fact, a third of all respondents in Miami $(n=17)$ reported experiencing more negative interactions with other Latinos than positive interactions. Even if disunion is not the norm in the interactions among the Latino communities, this finding constitutes a major finding that is widely underreported by the 
Latino Studies Volume 16 Number 1

ORIGINAL PAPER

existing literature on Latino studies, a field that has long implied intra-ethnic cooperation, social cohesion, and ethnic solidarity in the face of interethnic divisions (e.g., Portes and Stepick 1993).

There are three general, interrelated, and not mutually exclusive schools of thought regarding why Latinos of different national origins, races, and different intersecting identities would tend toward intra-ethnic cohesion and unity under a pan-ethnic label. The "Latino threat” narrative, a term coined by Chavez (2008), posits that Latinos of all kinds cleave together when the American political, social, and economic climate treats them as a single, monolithic, and dangerous group. Under threat, Latinos band together for protection. This is related to the second theory: that there is power in numbers. In her 2014 book, Making Hispanics, Cristina Mora detailed the decades-long purposeful construction of the "Hispanic" label as a quest for the group to be recognized, respected, counted, and protected. The third theory seeks to recognize and respect the collective latinidad as well, but focuses instead on the purported instinct toward solidarity around shared culture (Corlett 2003).

Immigrant Latinos are much less likely than native-born Latinos to feel pan-ethnic solidarity, or to embrace a pan-ethnic label like “Hispanic” or “Latino” (Beltrán 2010). As Barth (1969) asserted, groups do not have to be that different from one another in order to claim that they are, to seek to differentiate themselves from one another, or for those differences to have real implications. Systems of stratification determine which groups, however empirically similar they may be, get more or fewer resources (Massey 2007), and the Miami-Dade area is no exception. In the following subsections, we present our results by articulating them around the explanatory factors that recurred the most frequently in our data as the reasons that Latinos experience intra-group divisions: legal status, skin color, class and education, national origin, and regional origin. 
Latino Studies Volume 16 Number 1

ORIGINAL PAPER

As the interviews quoted below reflect, many participants responded to questions about their perceptions of and relationships with members of other Latino national origin groups with stereotypes. The authors would like to make it clear that we do not endorse these views, but still chose to share quotes that feature these views because they are representative of group attitudes and therefore describe intra-Latino dynamics in Miami.

\section{Legal status}

Our empirical evidence shows that structural factors divide the Latino communities in Miami. Group differences in legal status exacerbate divisions and entrench a hierarchy among Latinos. There is a legal hierarchy in terms of immigration policy and legal status among Caribbean Latinos. Puerto Ricans are automatic United States citizens because of the Jones Act of 1917 and can move back and forth between the island and the mainland and enjoy the privileges of citizenship in both locations. Cuban immigrants have been favorably treated by American immigration policy since the $1960 \mathrm{~s}^{1}$, and at present, if a Cuban migrant reaches American soil (as opposed to being intercepted in the water), they have easy access to a green card and eventual citizenship (Portes and Stepick 1993).

The preferential treatment Cubans and Puerto Ricans receive with regard to residency and citizenship is a source of tension among Latinos. In our sample, Continental Latin American Latinos are envious of those groups to whom citizenship came easily. During the interviews, the words “jealous,” “feel superior/inferior,” “unfair” and “abuse” were

\footnotetext{
${ }^{1}$ The Obama administration began to thaw American relations with Cuba in 2014 by rolling back economic sanctions against the island nation, reestablishing diplomatic relations between the two countries, engaging in cooperative efforts to curtail drug trafficking, permitting tourist travel, and allowing the use of American credit cards in Cuba, among other initiatives. Since taking office in January 2017, the Trump administration has drastically reduced the size of the American embassy in Cuba and has expelled 15 Cuban diplomats from their embassy in Washington. On 9 November 2017, the Trump administration implemented plans to return to more Cold War-like relations with Cuba, prohibiting travel except with Treasury Department-approved and guided tour groups, prohibiting any commercial transactions with ties to the Cuban government and military, and restricting trade with 180 State Department identified agencies (DeYoung 2017).
} 
Latino Studies Volume 16 Number 1

ORIGINAL PAPER

mentioned repeatedly. Sonja, a Nicaraguan immigrant, does not understand why some Latino national groups would be privileged above others for no apparent reason.

Here, especially the Cubans, they get everything, from the moment they arrive. They get jobs right away, while us, we don't even know where to look. When they arrive, they get the whole package: they get the nationality, they get benefits. How it that fair? ... Why them and not us? ${ }^{3}$

Immigrants internalize the preferences and status associated with this legal hierarchy, and its consequences manifest in other ways (see Horton 2004). These differential immigration policies foster resentment and prejudice and thus weaken ties among members of the group by emphasizing their differences. Arieta, a Mexican immigrant, explains that among Mexicans there is a pervasive stereotype that Cubans and Puerto Ricans abuse the system because they have access to more resources and social services than most Latino immigrants.

I . . . heard a lot that in New York it is very easy to get food stamps and so people say, "I have food stamps, [I] have a card worth five hundred [dollars]. Who wants it for four hundred?” They sell it and they use the cash to buy stuff and so on. ... I think it's Puerto Ricans and Cubans. These two are number one [groups who do that]. ${ }^{4}$

As a consequence of these different legal statuses and their perception by the different Latino communities, the members of the Latino communities experience life in the United States differently: the hierarchy among the Latino groups, artificially created based on the legal status, reinforces intra-group divisions and allows negative stereotypes to fester.

\section{Social class and educational attainment}

The interviews also reveal the importance of internal factors, such as educational attainment as a proxy for social class, which tends to divide Latinos (Meier and Melton 2012). Beyond socioeconomic status, class, as assessed by educational attainment, plays a key role in the intra-Latino group interactions. Unity is achieved more often when individuals possess higher levels of education. Leticia, a Mexican immigrant, exemplifies this: 
I think [unity] depends on the culture as well and the setting sometimes. [T] he more education people have, the better they treat you. . . . There are also Hispanics ... who are kind. ${ }^{5}$

So a perceived lack of education increases tensions among Latinos. Yamile, another Nicaraguan immigrant, says he feels that when Latinos lack education, they tend to treat others poorly, especially other Latinos:

This is what I was saying, you know, sometimes you go to a store where they all speak Spanish and if you ask them a question, they will treat you badly because that person comes from a place where she hasn't had any formal education. ${ }^{6}$

Educational attainment also figures into intra-Latino dynamics in a peculiar way. Half $(n=21)$ of the respondents who reported higher levels of division than solidarity among the Latino communities in Miami indicated that they trusted non-Latino whites more than coethnics. Almost all the interviewees explained their trust for “Americans” as being because Americans were better educated, and that higher education led to lower exploitation. Pablo, an Argentinian immigrant, invoked education in his interview:

In Miami, Latinos are very friendly, very open, because 80 percent of them, they want to use you. So as long as they see an opportunity, they are nice. The Americans I've met, at least here, in general, are good to us Latinos because they are used to working with us. And if they treat us badly, it's because they are racist or don't like Latinos, but not because they are trying to take advantage of you, so if they treat you badly it's because they have a problem with Latinos in general. Latinos, on the other hand, they treat you badly because they try to figure out how to screw you over, to say it bluntly. ... That doesn't happen with Americans, they are educated people, not like some of us. ... So in order for you not to notice, Latinos get all sweet and help you, and you get to like them, but at the moment of truth, they stab you in the back. ${ }^{7}$

\section{Race, skin color, and phenotype}

Analysis of the interviews further reveals that, among Latinos of all national origin groups who experienced more division than solidarity with their co-ethnics, race was consistently reported as a main cause of disunion among co-ethnics (85\% of them). This 
Latino Studies Volume 16 Number 1

ORIGINAL PAPER

could be because skin color and phenotype are the first visible criteria that differentiate

people: race represents a line between the members of the Latino communities and creates a hierarchy (Golash-Boza and Bonilla-Silva 2013; Anthias 2001). These same Latino

respondents report that racial discrimination and disunion often intersect with socioeconomic tensions. Orlando, ${ }^{8}$ a Cuban immigrant, exemplifies this. He explains that Latinos draw boundaries among themselves according to national origin, using race and class as proxies:

I think there is no unity as such. There are some communities, some . . . maybe some countries, some regions . . . [that] are somewhat united. But overall I do not think that the Latino community is very united, because there are Latinos who exploit Latinos. ... . And they discriminate. [Some] Latinos believe they are superior to others either because of their economic position in the region in which they used live. For instance, Latinos, sometimes Cubans themselves, they call you indio to make you feel inferior to the others. ${ }^{9}$

"Indio" is a pejorative term used to describe people of indigenous descent in Latin America. It derives from the interactions between Spanish colonists and the native peoples they encountered and conquered centuries ago (Golash-Boza and Bonilla-Silva 2013; Telles 2014). Here Orlando applies this age-old distinction to the Miami context, drawing a line between indios, who are of a darker complexion, and white Latinos, who occupy a higher racial position. The reference to indio, as opposed to another term like "black” or "dark," indicates that the Latin American racial formation categories are still relevant and applied in the Miami context.

Among the respondents who mentioned race, skin color, or phenotype during the interviews, and even among those who claim to be color-blind, race influences their perception of other Latinos. For instance, Roberto, a Cuban immigrant, explained that to him skin color did not dictate whether he would befriend someone.

I really don't care about skin color or race. I am friends with everyone, even if you're Black, a person of color. I'll call you using your name, I won't call you negro. We all have a name and to me we're all equal, Latinos, Africans, etcetera. . . I I am not a racist. ${ }^{10}$ 
However, as the interview progressed, Roberto was asked to discuss his experience with a particular social worker. He proceeded to do exactly what he claimed that he never did-that is, reference race:

That Black woman was really crazy! She helped me but really I couldn't stop but wonder what was wrong with her. [Attempts to imitate her voice and gesture.] What was the name of that Black woman? I can't remember. Black people can be weird sometimes.

With only a few exceptions ( $n=7)$, our interviews exemplify the process of secondary marginalization and show that Latinos reproduce the racial stratification and the behaviors of the dominant group, even the respondents who did not report disunion among their coethnics. Experiences like Orlando’s show that Latinos themselves are policing racial boundaries and enacting racial stratification at the micro level, even if the tropes used are both imported from Latin America and adopted from their host society. This racial stratification within and among the various Latino national groups sets the stage for tensions in the Latino communities, as skin color remains one of the factors used to create boundaries between "us" and "them” and thus prevent a fuller sense of cohesion among the various Latino groups (see Hochschild and Weaver 2007).

\section{National origin}

National origin emerges from the interviews as another key concept for explaining tensions between and among Latino communities. Although Latinos are commonly described in the literature and the media as sharing similar values, they do not necessarily relate easily to each other because of the prejudices that immigrants bring to the United States from their countries of origin regarding other national groups, or because of American prejudices they adopt after arrival. Once in the United States, Latinos oftentimes continue to use these 
Latino Studies Volume 16 Number 1

ORIGINAL PAPER

stereotypes as a way to socially distance themselves from other groups whom they perceive as negatively stigmatized in the host society.

Yamile explains that each national origin group comes with their own culture and that it is sometimes hard to find common ground with people who come from somewhere else:

When we are within our [ethnic] group, ... maybe then we're more united. But sometimes,. . . it's [like] oil and the vinegar. If you are from Colombia, and I am from Nicaragua, I talk about you [negatively]. ... When we are within our own community, perhaps there is a bit more unity. But among Latinos, I do not think so. ${ }^{11}$

The interviews show that these differing views about national origin groups and the associated practices translate into stereotypes and secondary marginalization of segments of the Latino communities. While secondary marginalization presents itself as a lack of panethnic unity among Latinos in Miami, when different national origin groups draw and reinforce intra-ethnic boundaries that differentiate them by class and culture, secondary marginalization also manifests through two regional groups’ perceptions of their cultural and moral standing and the resulting negative stereotypes that develop and spread. This last section shows that Latino respondents can be clearly delineated by regional origin.

\section{Caribbean Latinos versus continental Latinos}

Analysis of the interviews highlights a rift between Caribbean Latinos and Continental Latin American Latinos. Respondents perceived cultural differences-and propagated stereotypes_-based on the region of origin. The authors would like to repeat that we do not endorse these stereotypes. We only seek to understand their roots in systemic stratification, and their repercussions for intra-ethnic Latino cohesion and division.

The interviews reveal two distinct groups-Continental Latinos (including Central, North, and South American Latinos) and Caribbean Latinos—as do the ways in which these two groups speak about each other in order to create social distance and exert control over their ethnic identities. Our interviews show that this dichotomy/opposition between 
Latino Studies Volume 16 Number 1

ORIGINAL PAPER

Continental versus Caribbean Latinos is more prevalent among Latinos from continental Latin America, as almost 75\% of them categorize Latinos from the Caribbean together. Among Caribbean Latinos, this distinction was less clear, as they tend to further differentiate between Central American Latinos and Continental Latinos. Overall, Continental respondents appear to stereotype Caribbean Latinos as belonging to less stable and more fragmented families. They clearly separate "them” and "us” to show that the commonalities between them are reduced to a minimum (e.g., Spanish language).

This form of secondary marginalization is meant to further reinforce the hierarchizing among the Latino communities and to show how much more deserving they are. This is an attempt by some Latino groups to resemble non-Latino whites in a process of becoming what has been referred to as "honorary whites" (Bonilla-Silva 2002) and thereby climbing the social ladder. Anibal, a Nicaraguan immigrant, refused to be categorized with Latinos from the Caribbean. To him, Dominicans and Puerto Ricans "are very different from [Nicaraguans].” He supported this assertion with a socially distancing stereotype: that "their women have kids with different men, sometimes they don't know who the father is,” adding that "this doesn’t happen among us Nicaraguans." ${ }^{12}$ Nearly $80 \%$ of all respondents from continental Latin America indicate that these stereotypes about Caribbean Latinos are common among Continental Latinos. They cite these stereotypes when explaining why they are “different” from islanders. Continental Latinos who hold these negative views of Caribbean Latinos create a moral hierarchy, distancing themselves from Caribbean Latinos, who they place at the bottom of this hierarchy. For instance, another Continental Latino stereotype is that Caribbean Latinos are abusers of the American social safety net. Diego, a Colombian immigrant, explains that Continental Latinos do not want to associate with Caribbean Latinos because of this.

For example, some of us Colombians will do it [abuse the social safety net], but most of us won't. But the Puerto Ricans and Dominicans. . . . Listen, 
when I got here, I saw a pregnant woman and another woman who was saying to her, "You're pregnant again?" "Yes, to get welfare. It's what keeps us alive. I have three others, that one will make it four.” You see the difference in mentality? We are not like that. I'm not saying all Colombians, but we are not like that, there's a big difference. . . . We are a bit more reserved and respectful, not like the Dominicans and Puerto Ricans. ... The Salvadorans are also like us, quieter....We [Colombians and Salvadorans] mostly hang out together. ${ }^{13}$

These interviews reveal significant perceived cultural differences between Caribbean Latinos and Continental (North, Central, and South American) Latinos. These stereotypes and prejudices have negative impacts on group cohesion and pan-ethnic sentiment.

These were particularly salient with regard to legal status. For the Caribbean Latinos surveyed, particularly the Dominicans, being undocumented is considered shameful and therefore any means to remedy the situation is considered acceptable. ${ }^{2}$ During an interview, Freddy, a thirty-two-year-old Dominican, admitted that he married primarily to obtain permanent resident status. According to him, the end justifies the means: he would get deported if he did not regularize his status through marriage, therefore getting married increases the odds that he would be able to stay on US soil, even after taking into account the risk of getting caught and deported. When the interviewer asked him if he married to legalize his situation he responded, "Yes and no. ... It's just, that's how it goes here, it's almost normal.”14

Based on our data, Latinos from continental Latin America and from the Caribbean seem to form separate social networks: the networks of Caribbean Latinos seemed designed to circumvent the limitations of some immigrants’ status (e.g., fake marriages), while Continental Latinos tend to play more by the rules and keep a low profile.

Many Continental Latino respondents perceived Cubans, Dominicans, and Puerto Ricans as alike, sharing a set of unacceptable moral values that are distinct from those shared

\footnotetext{
2 This was the case for $75 \%$ of our Dominican respondents and $65 \%$ of our Cuban respondents.
} 
by the rest of the Latino community. When asked about these stereotypes and their validity, over half of our Caribbean Latino respondents argued that they were simply a more resourceful people. For example, Yolanda, a Dominican immigrant, replied,

It's like Dominicans come to the US and fight to get their green card. One way or another, they get their green card. However, someone from another culture may come and live here illegally for twenty, thirty years and never try to become a legal resident. ... So this forms a barrier between us [Dominicans vs. Latinos from Latin America].

Conversely, for Latinos from continental Latin America, even though living in the proverbial shadows brings many constraints, the interviews highlighted that none of them were willing to use green card marriages to stay in the United States. Continental Latino interviewees were uncomfortable talking about it and find fault with those who engage in those arrangements. They draw a moral line between what is acceptable and what is not, and thus a line between them and Latinos from the Caribbean.

\section{Interrogating the narrative of pan-ethnic social cohesion}

While most Latino studies literature focuses on intra-ethnic solidarity, this paper used in-depth, semi-structured interviews with immigrants in Miami Dade County, Florida, to investigate the prospect of intra-ethnic divisions. Since only a third of our respondents reported experiencing more division that cohesion overall, our findings do not represent a comprehensive/holistic view of co-ethnic interactions among the Latino communities in Miami. Our goal is not to invalidate or reject the use of the pan-ethnic label, and we recognize the instrumental use of the pan-ethnic label, and pan-ethnic solidarity, in the contexts in which cohesion is exhibited, such as when Latinos feel discriminated against by non-Latinos.

The analysis highlights divisions among the pan-ethnic groups that constitute the different Latino communities in Miami to bring depth to the literature and thus improve scholarly understanding of intra-group interactions. 
Latino Studies Volume 16 Number 1

ORIGINAL PAPER

Our results indicate that cohesion among Latino communities is far from organic or self-evident because a number of factors limit social cohesion within the Latino community; pan-ethnic solidarity is fragile because of national and regional origin group differences, both real and perceived, that tend to override the power of real or perceived commonalities. We find that Latino immigrants experience secondary marginalization from their peers, who display a form of social separatism across lines of national origin, race, and class, which can translate into discriminatory acts and segregation based on socioeconomic status as well as physical criteria (e.g., skin color), legal status, and preconceived ideas about other groups. When national and class divisions are more marked than the elements held in common, intracommunitarian relations can therefore act as a brake on unity. Latinos associate behaviors with certain national groups and, in so doing, reinforce stereotypical images and facilitate secondary marginalization. This is particularly the case between Latinos from the Caribbean (Dominicans, Puerto Ricans, and Cubans, especially those from later waves of immigration) and Latinos from Continental Latin America. We argue that interactions among these groups, or lack thereof, facilitate the development and perpetuation of negative stereotypes.

Even in this unique majority-Latino metropolitan area, the authors found evidence of secondary marginalization within the Latino community by race, class, and national origin. Despite the fact that Miami is a predominantly Latino area, and an older immigrant gateway, existing structures of racial and socioeconomic stratification that privilege non-Hispanic whites to the detriment of Latinos still operate in Miami-Dade. Furthermore, Miami has experienced waves of immigration from newer sending countries in recent years, so it is no longer a strictly Cuban enclave, leaving room for Latinos of more national groups to settle in cohesion and competition with one another.

Our findings are critical because understanding the mechanisms behind disunion can similarly lead scholars, community organizers, and other leaders toward understanding social 
Latino Studies Volume 16 Number 1

ORIGINAL PAPER

cohesion. Indeed, scholars, political actors, and media elites need to question co-ethnic concordance, and the myth of the Latino monolith, in public policy as well as the public narrative.

\section{References}

Aguilar, E. 2009. Asimilación Laboral de Los Inmigrantes Colombianos En Estados Unidos. (Spanish). Revista de Economía Del Rosario 12 (1): 67-93.

Alba, R., T. Jiménez, and H. Marrow. 2014. Mexican Americans as a Paradigm for Contemporary Intra-Group Heterogeneity. Ethnic and Racial Studies 37 (3): 446-466.

Anthias, F. 2001. The Concept of "Social Division” and Theorising Social Stratification: Looking at Ethnicity and Class. Sociology 35 (4): 835-854.

Aranda, E. 2007. Struggles of Incorporation among the Puerto Rican Middle Class. Sociological Quarterly 48 (2): 199-228.

Aranda, E., S. Hughes, and E. Sabogal. 2014. Making a Life in Multiethnic Miami: Immigration and the Rise of a Global City. Boulder, CO: Lynne Rienner.

Beltrán, C. 2010. The Trouble with Unity: Latino Politics and the Creation of Identity. New York: Oxford University Press.

Barth, F. 1969. Ethnic Groups and Boundaries: The Social Organization of Culture Difference. Boston: Little, Brown.

Bohon, S. 2013. Latinos in Ethnic Enclaves: Immigrant Workers and the Competition for Jobs. Hoboken, NJ: Taylor and Francis.

Bonilla-Silva, E. 2002. "We are all Americans!”: The Latin Americanization of Racial Stratification in the USA. Race and Society 5 (1) : 3-16.

Brown, E., and F. Brooks. 2006. African American and Latino Perceptions of Cohesion in a Multiethnic Neighborhood. American Behavioral Scientist 50 (2): 258-275.

Calderón, J. 1992. "Hispanic” and "Latino”: The Viability of Categories for Panethnic Unity. Latin American Perspectives 19 (4): 37-44.

Carey, T., T. Matsubayashi, R. Branton, and V. Martinez-Ebers. 2013. The Determinants and Political Consequences of Latinos’ Perceived Intra-Group Competition. Politics, Groups, and Identities 1 (3): 311-328.

Catanzarite, L., and M. B. Aguilera. 2002. Working with Co-Ethnics: Earnings Penalties for Latino Immigrants at Latino Jobsites. Social Problems 49 (1): 101-127. 
Latino Studies Volume 16 Number 1

ORIGINAL PAPER

Chavez, L. 2008. The Latino Threat: Constructing Immigrants, Citizens and the Nation. Stanford, CA: Stanford University Press.

Cobas, J., J. Duany, and J. Feagin. 2009. Racializing Latinos: Historical Background and Current Forms. In How the United States Racializes Latinos: White Hegemony and Its Consequences, edited by J. Cobas, J. Duany, and J. Feagin, 1-14. Boulder, CO: Paradigm.

Cohen, C. 1999. The Boundaries of Blackness: AIDS and the Breakdown of Black Politics. 1st ed. Chicago: University of Chicago Press.

Corlett, A. 2003. Race, Racism, and Reparations. Ithaca, NY: Cornell University Press

De Genova, N., and A. Ramos-Zayas. 2003. Latino Crossings: Mexicans, Puerto Ricans and the Politics of Race and Citizenship. New York: Routledge.

DeYoung, Karen. 2017. "White House Implements New Cuba Policy Restricting Travel and Trade,” The Washington Post, 8 November.

https://www.washingtonpost.com/world/national-security/white-house-implements-newcuba-policy-restricting-travel-and-trade/2017/11/08/a5597dee-c49b-11e7-aae0cb18a8c29c65_story.html?utm_term=.273ce3fe0bf8

Dzidzienyo, A., and S. Oboler, eds. 2005. Neither Enemies Nor Friends: Latinos, Blacks, Afro-Latinos. New York: Palgrave MacMillan.

Fernández, L. 2012. Brown in the Windy City. Chicago: University of Chicago Press.

Frey, W., and R. Farley. 1996. Latino, Asian, and Black Segregation in U.S. Metropolitan Areas: Are Multi-Ethnic Metros Different? Demography 33 (1): 35-50.

Garcia Bedolla, L. 2005. Fluid Borders: Latino Power, Identity, and Politics in Los Angeles. Berkeley: University of California Press.

Garcia Bedolla, L. 2014. Latino Politics. Cambridge, MA: Polity Press.

Golash-Boza, T., and E. Bonilla-Silva. 2013. Rethinking Race, Racism, Identity and Ideology in Latin America. Ethnic and Racial Studies 36 (10): 1485-1489.

Grenier, G., L. Pérez, and N. Foner. 2002. The Legacy of Exile: Cubans in the United States. 1st ed. Boston: Allyn and Bacon.

Grosfoguel, R. 1999. Puerto Ricans in the USA: A Comparative Approach. Journal of Ethnic and Migration Studies 25 (2): 233-249.

Guarnaccia, P., I. Martinez Pincay, M. Alegria, P. Shrout, R. Lewis-Fernandez, and G. Canino. 2007. Assessing Diversity among Latinos: Results from the NLAAS. Hispanic Journal of Behavioral Sciences 29 (4): 510-534. 
Latino Studies Volume 16 Number 1

ORIGINAL PAPER

Guarnizo, L., A. Sanchez, and E. Roach. 1999. Mistrust, Fragmented Solidarity, and Transnational Migration: Colombians in New York City and Los Angeles. Ethnic and Racial Studies 22 (2): 367-396.

Hochschild, J., and V. Weaver. 2007. The Skin Color Paradox and the American Racial Order. Social Forces 86 (2): 643-670.

Horton, S. 2004. Different Subjects: The Health Care System’s Participation in the Differential Construction of the Cultural Citizenship of Cuban Refugees and Mexican Immigrants. Medical Anthropology Quarterly 18 (4): 472-489.

Jiménez, Tomás R. 2010. Affiliative Ethnic Identity: A More Elastic Link between Ethnic Ancestry and Culture. Ethnic and Racial Studies 33 (10): 1756-1775.

Johnson, K. 2004. Law and Politics in Post-Modern California: Coalition or Conflict between African Americans, Asian Americans, and Latina/os? Ethnicities 4 (3): 381-401.

Lavariega Monforti, J., and G. Sanchez. 2010. The Politics of Perception: An Investigation of the Presence and Sources of Perceptions of Internal Discrimination among Latinos. Social Science Quarterly 91 (1): 245-265.

Maldonado, M. 2009. “It Is Their Nature to Do Menial Labour”: The Racialization of “Latino/a Workers” by Agricultural Employers. Ethnic and Racial Studies 32 (6): 10171036.

Marrow, H. 2011. New Destination Dreaming: Immigration, Race, and Legal Status in the Rural American South. Stanford, CA: Stanford University Press.

Massey, D. 2007. Categorically Unequal: The American Stratification System. New York: Russell Sage.

McClain, P., N. Carter, V. DeFrancesco Soto, M. Lyle, J. Grynaviski, S. Nunnally, T. Scotto, J. Kendrick, G. Lackey, and K. Davenport Cotton. 2006. Racial Distancing in a Southern City: Latino Immigrants’ Views of Black Americans. Journal of Politics 68 (3): 571-584.

Meier, K., and E. Melton. 2012. Latino Heterogeneity and the Politics of Education: The Role of Context. SSQU Social Science Quarterly 93 (3): 732-749.

Miami-Dade County QuickFacts from the US Census Bureau. 2015. http://quickfacts.census.gov/qfd/states/12/12086.html.

Miami-Dade County, Department of Planning and Zoning 2011. https://www.miamidade.gov/planning/library/reports/data-flash/2011-hispanics-byorigin.pdf. 
Latino Studies Volume 16 Number 1

ORIGINAL PAPER

Milkman, R. 2007. Labor Organizing among Mexican-Born Workers in the United States

Recent Trends and Future Prospects. Labor Studies Journal 32 (1): 96-112.

Mora, G. C. 2014. Making Hispanics: How Activists, Bureaucrats, and Media Constructed a New American. Chicago: University of Chicago Press.

Ochoa, G. L. 2000. Mexican Americans’ Attitudes toward and Interactions with Mexican

Immigrants: A Qualitative Analysis of Conflict and Cooperation. Social Science

Quarterly 81 (1): 84-105.

Padilla, F. 1985. Latino Ethnic Consciousness: The Case of Mexican Americans and Puerto Ricans in Chicago. Notre Dame, IN: University of Notre Dame Press.

Perez, L. 1986. Immigrant Economic Adjustment and Family Organization: The Cuban Success Story Reexamined. International Migration Review 20 (1): 4-20.

Pew Hispanic Center. 2015. Facts on U.S. Immigrants, 2015: Statistical Portrait of the ForeignBorn Population in the United States.

http://www.pewhispanic.org/2017/05/03/facts-on-u-s-immigrants-current-data/

Phinney, J., G. Horenczyk, K. Liebkind, and P. Vedder. 2001. Ethnic Identity, Immigration, and Well-Being: An Interactional Perspective. Journal of Social Issues 57 (3): 493-510.

Phinney, J., and A. Ong. 2007. Conceptualization and Measurement of Ethnic Identity:

Current Status and Future Directions. Journal of Counseling Psychology 54 (3): 271281.

Portes, A., and R. Rumbaut. 2001. Legacies: The Story of the Immigrant Second Generation.

Berkeley: University of California Press.

Portes, A., and A. Stepick. 1993. City on the Edge: The Social Transformation of Miami. Berkeley: University of California Press.

Sabatier, C. 2008. Ethnic and National Identity among Second-Generation Immigrant Adolescents in France: The Role of Social Context and Family. Journal of Adolescence 31 (2): 185-205.

Sanchez, G. 2006. The Role of Group Consciousness in Latino Public Opinion. Political Research Quarterly 59 (3): 435-446.

Stepick, A., and C. Dutton Stepick. 2002. Becoming American, Constructing Ethnicity: Immigrant Youth and Civic Engagement. Applied Developmental Science 6 (4): 246-257. 
Latino Studies Volume 16 Number 1

ORIGINAL PAPER

Telles, E. 2014. Pigmentocracies: Ethnicity, Race, and Color in Latin America. Chapel Hill: University of North Carolina Press.

Telles, E., and V. Ortiz. 2009. Generations of Exclusion: Mexican Americans, Assimilation, and Race. New York: Russell Sage.

Tovar, J., and C. Feliciano. 2009. “Not Mexican-American, but Mexican”: Shifting Ethnic Self-Identifications among Children of Mexican Immigrants. Latino Studies 7 (2): 197221.

Weaver, C. 2007. The Effects of Contact on the Prejudice between Hispanics and NonHispanic Whites in the United States. Hispanic Journal of Behavioral Sciences 29 (2): 254-274.

Woltman, K., and K. Newbold. 2009. Of Flights and Flotillas: Assimilation and Race in the Cuban Diaspora. Professional Geographer 61 (1): 70-86. 


\section{Latino Studies Volume 16 Number 1}

ORIGINAL PAPER

Figure 1: Respondent Profile

\begin{tabular}{|c|c|c|c|c|c|c|}
\hline $\begin{array}{c}\text { Interview } \\
\# \\
\end{array}$ & GENDER & ORIGIN & AGE & IMM. STATUS & TIME IN US & EDUCATION \\
\hline 1 & Female & Nicaraguan & $50-59$ & naturalized citizen & $15+$ years & some high school \\
\hline 2 & Male & Cuban & $50-59$ & legal permanent resident & $<5$ years & graduate school \\
\hline 3 & Male & Nicaraguan & $50-59$ & legal permanent resident & 10-15 years & high school diploma \\
\hline 4 & Female & Colombian & $40-49$ & legal permanent resident & 5-10 years & high school diploma \\
\hline 5 & Female & Colombian & $30-39$ & legal permanent resident & 5-10 years & high school diploma \\
\hline 6 & Female & Venezuelan & $30-39$ & naturalized citizen & 10-15 years & less than high school \\
\hline 7 & Male & Cuban & $40-49$ & refugee/special program & $<5$ years & some college \\
\hline 8 & Male & Cuban & $60+$ & legal permanent resident & $<5$ years & some college \\
\hline 9 & Female & Cuban & $60+$ & legal permanent resident & $<5$ years & some high school \\
\hline 10 & Female & Cuban & $30-39$ & legal permanent resident & $<5$ years & some high school \\
\hline 11 & Female & Nicaraguan & $30-39$ & undocumented & $<5$ years & college \\
\hline 12 & Female & Dominican & $50-59$ & legal permanent resident & $15+$ years & college \\
\hline 13 & Female & Dominican & $50-59$ & naturalized citizen & $15+$ years & high school diploma \\
\hline 14 & Male & Cuban & $60+$ & legal permanent resident & $15+$ years & college \\
\hline 15 & Female & Mexican & $30-39$ & undocumented & 5-10 years & college \\
\hline 16 & Male & Cuban & $18-29$ & refugee/special program & $<5$ years & high school diploma \\
\hline 17 & Female & Cuban & $18-29$ & legal permanent resident & $5-10$ years & college \\
\hline 18 & Female & Dominican & $18-29$ & legal permanent resident & $<5$ years & high school diploma \\
\hline 19 & Male & Cuban & $40-49$ & legal permanent resident & $<5$ years & college \\
\hline 20 & Female & Dominican & $18-29$ & naturalized citizen & $15+$ years & high school diploma \\
\hline 21 & Male & Nicaraguan & 30-39 & naturalized citizen & $15+$ years & some college \\
\hline 22 & Male & Colombian & $30-39$ & legal permanent resident & 10-15 years & some college \\
\hline 23 & Female & Mexican & $18-29$ & legal permanent resident & 10-15 years & high school diploma \\
\hline 24 & Female & Mexican & $18-29$ & undocumented & $15+$ years & college \\
\hline 25 & Male & Mexican & $30-39$ & undocumented & $15+$ years & college \\
\hline 26 & Female & Honduran & $30-39$ & undocumented & $<5$ years & some college \\
\hline 27 & Male & Argentinian & $30-39$ & legal permanent resident & $15+$ years & high school diploma \\
\hline 28 & Male & Cuban & $30-39$ & legal permanent resident & $5-10$ years & high school diploma \\
\hline 29 & Female & Dominican & $40-49$ & naturalized citizen & $15+$ years & some college \\
\hline 30 & Male & Cuban & $30-39$ & undocumented & $<5$ years & high school diploma \\
\hline 31 & Female & Nicaraguan & $60+$ & naturalized citizen & $15+$ years & \\
\hline 32 & Male & Cuban & $40-49$ & legal permanent resident & 5-10 years & \\
\hline 33 & Male & Cuban & $40-49$ & legal permanent resident & $5-10$ years & some high school \\
\hline 34 & Female & Colombian & $30-39$ & undocumented & 5-10 years & some high school \\
\hline 35 & Male & Cuban & $60+$ & legal permanent resident & $15+$ years & college \\
\hline 36 & Female & Cuban & $30-39$ & legal permanent resident & $<5$ years & \\
\hline 37 & Female & Dominican & $50-59$ & legal permanent resident & 5-10 years & \\
\hline 38 & Female & Argentinian & $18-29$ & undocumented & 10-15 years & high school diploma \\
\hline 39 & Female & Colombian & $30-39$ & undocumented & $<5$ years & \\
\hline 40 & Female & Venezuelan & $60+$ & naturalized citizen & $15+$ years & \\
\hline 41 & Female & Cuban & $18-29$ & legal permanent resident & $<5$ years & high school diploma \\
\hline 42 & Female & Cuban & $30-39$ & legal permanent resident & $5-10$ years & \\
\hline 43 & Female & Cuban & $60+$ & refugee/special program & $15+$ years & \\
\hline 44 & Female & Dominican & $50-59$ & naturalized citizen & $15+$ years & some college \\
\hline 45 & Male & Dominican & $30-39$ & Undocumented & 5-10 years & Some college \\
\hline
\end{tabular}


Latino Studies Volume 16 Number 1

ORIGINAL PAPER

\section{Notes}

${ }^{1}$ All the Spanish-speaking countries of North, Central, and South America, as well as the Caribbean, are represented in the original dataset of over 200 interviews conducted in Boston, Los Angeles, and Miami.

${ }^{2}$ Although Puerto Ricans are considered US citizens, they were included in this analysis because of their sizeable numbers in Miami, in order to better represent the interactions between the various Latino communities in Miami.

${ }^{3}$ Interview no. 11

${ }^{4}$ Interview no. 15

${ }^{5}$ Interview no. 24

${ }^{6}$ Interview no.33

${ }^{7}$ Interview no. 27

${ }^{8}$ All the names of the respondents were changed.

${ }^{9}$ Interview no.31

${ }^{10}$ Interview no.7

${ }^{11}$ Interview no.33

${ }^{12}$ Interview no. 21

${ }^{13}$ Interview no.22

${ }^{14}$ Interview no.45 